\title{
Population dynamics of safflower capsule flies (Diptera: Tephritidae) in Kohgiluyeh safflower farms of Iran
}

\author{
K. Saeidi, ${ }^{1}$ S. Mirfakhraei, ${ }^{2}$ F. Mehrkhou² \\ ${ }^{1}$ Department of Plant Protection, Agricultural and Natural Resources Research and Education \\ Center, Kohgiluyeh va Boyerahmad Province, Yasouj; ' 2 Department of Plant Protection, College of \\ Agriculture, Urmia University, Urmia, Iran
}

\begin{abstract}
Oilseeds such as flax, canola, safflower, soybean and sunflower, which are annual plants, provide the world's major source of vegetable oils, although the highest oil yield comes from oil-bearing tree fruits. One of the most popular oil seeds is safflower (Carthamus tinctorius L.), which belongs to the Asteraceae family. Due to the ability of this plant to grow in dry and semi-dry conditions, safflower oil has the potential to be a commercially profitable product in Iran. Seasonal populations of safflower capsule flies were studied in Kohgiluyeh safflower farms, Iran, from March to May in 2008 and 2009. Four yellow sticky traps were used to monitor populations of fruit flies in the safflower farms. Traps were checked once a week during the sampling period. The traps were emptied weekly into insect collection vials containing 70\% ethanol. Data were analysed with a two-way ANOVA. The relation between abiotic factors and species abundance was analysed with multiple linear regression. The results emphasized that Acanthiophilus helianthi was the most serious pest of safflower under the ecological conditions found in Gachsaran, being present in the field throughout three months of the year (March to May). Chaetorellia carthami was present in safflower fields from March to May, but in significant numbers only during April and May. Terellia
\end{abstract}

Correspondence: Karim Saeidi, Department of Plant Protection, Agricultural and Natural Resources Research and Education Center, Kohgiluyeh va Boyerahmad Province, P.0. Box 351, Yasouj, Iran.

Tel.: +98.741.3334821/+98.741.3334821 - Fax: +98.741.3334011.

E-mail: saeidi391@yahoo.com

Key words: Fruit flies; Acanthiophilus helianthi; Chaetorellia carthami; Terellia luteola; population fluctuation; Kohgiluyeh va Boyerahmad province.

Received for publication: 1 September 2014.

Revision received: 27 March 2015.

Accepted for publication: 30 April 2015.

(C) Copyright K. Saeidi et al., 2015

Licensee PAGEPress, Italy

Journal of Entomological and Acarological Research 2015; 47:4684 doi:10.4081/jear.2015.4684

This article is distributed under the terms of the Creative Commons Attribution Noncommercial License (by-nc 3.0) which permits any noncommercial use, distribution, and reproduction in any medium, provided the original author(s) and source are credited. luteola was present in safflower fields from March to May and in significant numbers only in late April, it does not seem to be a serious pest in safflower farms under Gachsaran's ecological conditions.

\section{Introduction}

Safflower (Carthamus tinctorius $\mathrm{L}$.) is a member of the Compositae or Asteraceae family (Emongor, 2010). It is a multi-purpose oilseed crop grown mainly for its high quality edible oil, as well as for bird seed (Karimi, 2000). Initially, safflower oil was used as a source of oil in the manufacture of paint, but today it is widely used as edible oil for cooking, and in the production of margarine and salad oil (Tinay, 2001). Safflower is also grown for its flowers, which are used as; cut flowers, in colouring and food flavouring, for the manufacture of dyes for the textile industry, livestock forage, as vegetable, herbal teas and for medicinal purposes (Karegar et al., 2004). In China, safflower is grown as a medicinal plant for the treatment of cardiovascular diseases, male and female fertility, lowering blood cholesterol, as well as various types of rheumatism and respiratory diseases (Rennie et al., 2003).

Safflower, is now cultivated on approximately one million hectares of land and annually about 700,000 tons of seed are produced (Zeynali, 2001). Iran, once known as Persia, used to be a centre for the commercial cultivation of safflower in the ancient world and it continues to cultivate this oil seed to this day (Golkar et al., 2010). At present, approximately 1000 hectares of land are under safflower cultivation in Iran, which produces approximately 700 tons of seed annually (Karegar et al., 2004). Due to the ability of the plant to thrive in arid and semi-arid lands, safflower has the potential to become a commercially profitable product in Iran (Karimi, 2000).

Like other crops, safflower is susceptible to various diseases and insect attacks (Majidi et al., 2011). Due to water restrictions and the amount of arable land, one of the methods used to increase production is to reduce the damage caused by pests and plant diseases.

In nature, insect populations fluctuate depending on environmental factors. Broadly speaking, these environmental factors can be divided into biotic factors, such as natural enemies and plants, and abiotic factors, such as temperature, relative humidity and precipitation. From ecological studies, vital information can be obtained by monitoring changes in insect population numbers that result from changes in environmental factors. Studies of potential pests are necessary in order to meet the challenges of providing protection for both crops and livestock (Den \& Walton, 1997).

Fruit flies of the family Tephritidae (Order: Diptera) are one of the most serious pests of fruits and vegetables. They cause enormous economic losses in the production of fruits and vegetables throughout the world (Korneyev \& Konovalov, 2010). In the Iranian province of 
Kohgiluyeh va Boyerahmad, there are 18 known species of fruit flies, however, the species considered to be the most serious pests of fruits and vegetables number less than ten (Gilasian \& Merz, 2008). The majority of these species are polyphagous, with high fecundity and the ability to spread quickly over a wide area, thus making them serious pests for the growers of fruits and vegetables.

Effective management of this fly on safflower crops requires a better understanding of the species' seasonal dynamics in a particular locality. To achieve effective pest control measures, actions need to be targeted at periods of maximum population build-up and at the most vulnerable stage of the crop (Saeidi, 2006). The present study was carried out to monitor population fluctuations of fly species associated with safflower damage in the Gachsaran region of Iran.

Despite the fact that the threat of pest infestation is a serious problem that hinders the cultivation of safflower on a commercial scale, no comprehensive or useful information about safflower pests in Kohgiluyeh va Boyerahmad Province and other parts of the country could be found.

\section{Materials and methods}

\section{Study site}

Kohgiluyeh-va-Boyerahmad is a mountainous province situated in South West of Iran. About 3/4 of the area is rugged and plains comprise only $1 / 4$ of the province area (Figure 1). The study was performed from March to May in 2008 and 2009 at the safflower farm in the Agricultural Research Station, Gachsaran. This site has a warm climate (mean minimum temperature of $15^{\circ} \mathrm{C}$ and a mean maximum temperature of $46^{\circ} \mathrm{C}$ ), and it is characterized by annual precipitation of about $250-300$ $\mathrm{mm}$. The total land area of the safflower farm surveyed covered an area of 0.5 ha. The site was selected because it represented a large area of cultivated safflower that is commonly infested by fruit flies.

\section{Fly trapping}

Four yellow sticky traps were used to monitor the populations of fruit flies in the safflower farm. The traps were composed of polyethylene plates with dimensions $20 \times 20 \mathrm{~cm}$ produced by the Agro science British Company. The traps were installed at a height of $80 \mathrm{~cm}$ from the ground, $200 \mathrm{~m}$ away from the field edge and $800 \mathrm{~m}$ apart from each other. Traps were checked once a week during the sampling period. The sticky traps were completely cleaned after each survey and re-glued if necessary.

\section{Collection and identification of traps catches}

The traps were emptied weekly into insect collection vials containing $70 \%$ ethanol. The insects collected were sent to a laboratory for identification and counting. Identification was based on the morphological characteristics of the collected specimens using a taxonomic key developed by the Iranian Fruit Fly Initiative (Mohamadzade Namin et al., 2010). Samples of the identified insects have been deposited at the Department of Plant Protection, Agricultural and Natural Resources Research Center of Yasouj, Iran.

\section{Incubation of flower heads}

Each week 50-safflower flower heads were collected and placed into plastic vessels. The mean room temperature during the incubation period was $23^{\circ} \mathrm{C}$, while the relative humidity for the same period varied between $55 \%$ and $60 \%$. The flower heads were inspected every other day to remove fruit flies pupae, until there no were pupae present in the flower heads. The pupae were then placed in plastic bottles (diameter $8 \mathrm{~cm}$ and height $15 \mathrm{~cm}$ ) lined at the bottom with moist tissue paper for emergence. Emerged flies were collected by aspirator and then counted.

\section{Climatic data}

Data on temperature, precipitation and relative humidity of the study area were obtained from the local weather station at the Gachsaran Agricultural Research Station.

\section{Data analysis}

Data was subjected to two-way ANOVA. The correlation between abiotic factors and species abundance was analyzed with SPSS multiple linear regression.

\section{Results and discussion}

\section{Relationship of safflower capsule flies and abiotic factors}

A total of 7633 fruit flies were captured in the yellow sticky traps during both years, and consisted of 88.8\% (6780) A. helianthi, 7.6\% (585) C. carthami and $3.5 \%$ (268) T. luteola. In addition, 854 fruit flies emerged from the incubated flower heads of which 70.8\% (605) were $A$. helianthi, $20.0 \%$ (171) C. carthami and 9.1\% (78) T. luteola.

A total of 3446 fruit flies were captured in the yellow sticky traps from March to May 2008. There was a significant difference among months in 2008 [degree of freedom $(\mathrm{df})=2 ; \mathrm{F}=3.59 ; \mathrm{P}=0.041$ ]. The highest

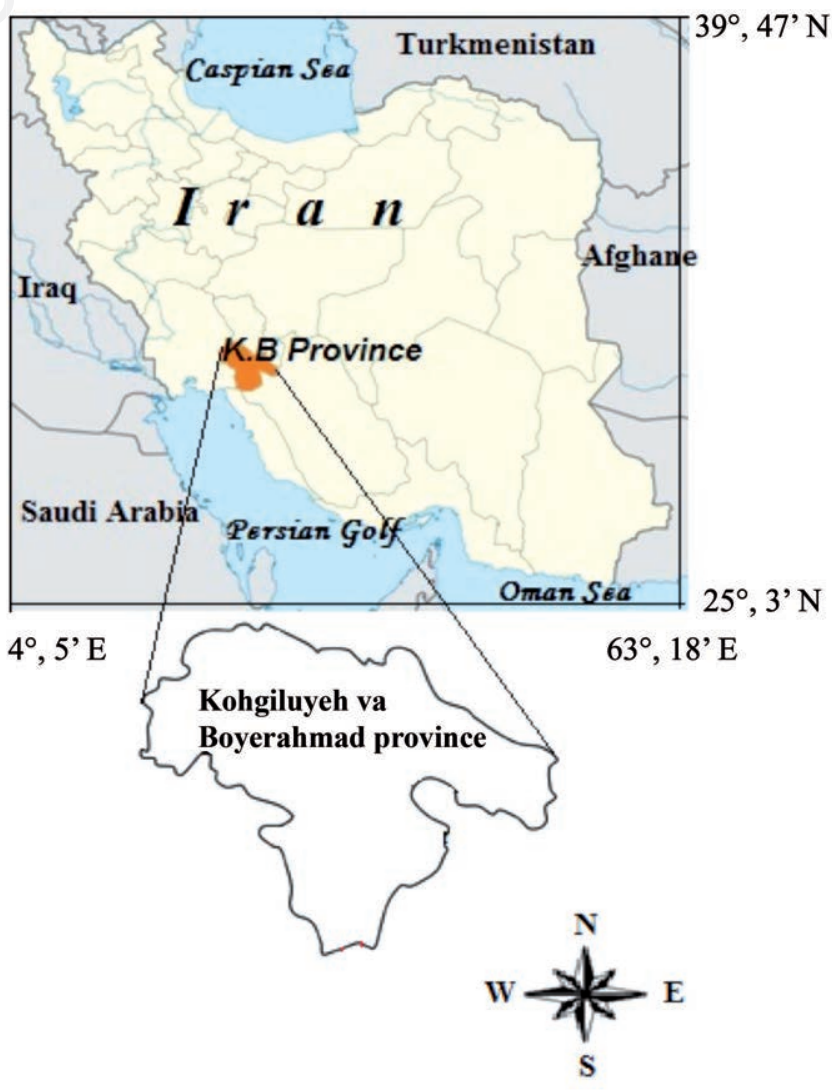

Figure 1. The geographical position of Kohgiluyeh va Boyerahmad province on map of Iran (Saeidi et al., 2015). 
number of individuals was obtained in May (Figure 2), and the number of flies captured of each species was also significantly different $(\mathrm{df}=2$; $\mathrm{F}=133.72 ; \mathrm{P}=0.000$ ). The highest number of specimens came from $A$. helianthi (3780), followed by C. carthami (296) and T. luteola (111) (Figure 3). Acanthiophilus helianthi was the species with the highest number of individuals $(\mathrm{P}<0.05)$ emerging from incubated flower heads with $225(63.2 \%)$ individuals, followed by $C$. carthami and T. luteola with $101(28.3 \%)$ and $30(8 \%)$ specimens, respectively (Table 1).

Similar results were obtained in 2009. A total of 4187 fruit flies were captured in the yellow sticky traps from March to May 2009. There was a significant difference found in the various months in 2009 ( $\mathrm{df}=2$; $\mathrm{F}=6.46 ; \mathrm{P}=0.005)$. The highest number of specimens was obtained in May (Figure 4), and the number of flies captured was also significantly different between species $(\mathrm{df}=2 ; \mathrm{F}=133.72 ; \mathrm{P}=0.000)$. The highest number of individuals belonged to A. helianthi (3000), followed by $C$. carthami (289) and T. luteola (157) (Figure 5). Acanthiophilus helianthi was still the most significant species $(\mathrm{P}<0.05)$ with the highest number of individuals emerging from incubated flower heads at 380 (76.3\%) individuals, followed by $C$. carthami and T. luteola with 70 (14\%) and 48 (9.6\%) specimens, respectively (Table 2).

Examining damaged safflower's flower heads across the semi-arid areas in Kohgiluyeh va Boyerahmad Province, in the south-west of Iran, it was observed that the safflower capsule fly and two other flies, namely Terellia luteola and Chaetorellia carthami, were infecting the flower heads of this crop. Overall, A. helianthi was the most abundant insect species.

Figure 6 gives population dynamics of the different fruit fly species during the study period (2008). The number of flies per trap per week for $A$. helianthi was significantly higher $(\mathrm{P}<0.05)$ in the three months from March to May than those for $C$. carthami and T. luteola. Actually, there was no significant difference found between $C$. carthami and $T$. luteola numbers. The highest number of flies per trap per week for $A$. helianthi was recorded in mid-May, while the highest catch for $C$. carthami was recorded in early May. Whereas, the highest trap catch for T. luteola was recorded at the end of March and April.

Table 2 shows the number of fruit fly species coming from incubated flower heads during the study period (2009). The trapped numbers for the three fruit fly species were not significantly different $(\mathrm{P}<0.05)$. The mean number of $A$. helianthi captured during the study was significantly higher than those of $C$. carthami and T. luteola. A. helianthi was the most dominant $(\mathrm{P}<0.05)$ fruit fly species that emerged from the incubated fruits during the peak safflower months from March to May.

Table 3 shows the correlations matrix for the three fruit fly species. The occurrence of $A$. helianthi was negatively correlated with that of $C$. carthami. The occurrence of $A$. helianthi was also negatively correlated with temperature, but positively correlated with relative humidity. However, populations of $C$. carthami were positively correlated with temperature, but negatively correlated with both relative humidity and rainfall. Populations of T. luteola did not show any significant correlations in these measures.

\section{Relationship of safflower capsule flies and abiotic factors (2009)}

A total of 4187 fruit flies were captured in the yellow sticky traps from March to May 2009. Out of these $90.2 \%$ (3780) were A. helianthi, $7.1 \%$ (296) C. carthami and 2.6\% (111) T. luteola. In addition, 498 fruit flies emerged from the incubated flower heads of which $76.3 \%$ (380) were $A$. helianthi, 14\% (70) C. carthami and 9.6\% (48) T. luteola (Table 2).

Figure 7 shows population dynamics of the different fruit fly species during the study period (2009). The number of flies per trap per week for A. helianthi was significantly higher (P 0.05) in the three months from March to May, than those for C. carthami and T. luteola. In fact,

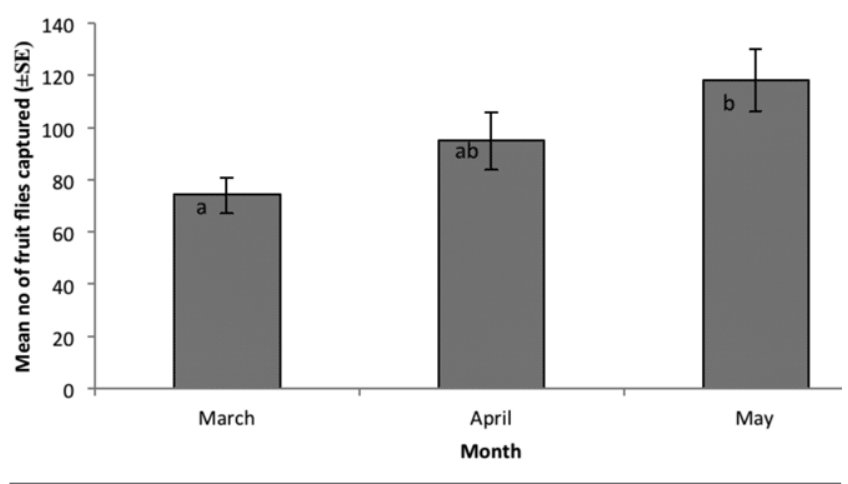

Figure 2. Number of safflower capsule flies found in different months 2008.

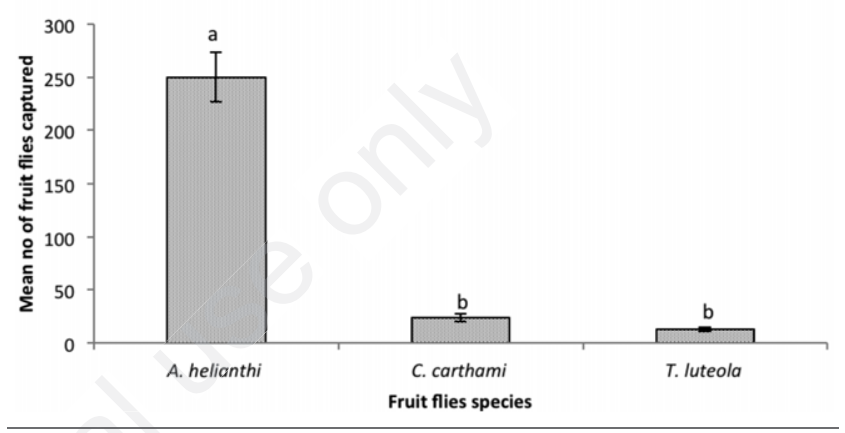

Figure 3. Number of safflower capsule flies for each species in 2008.

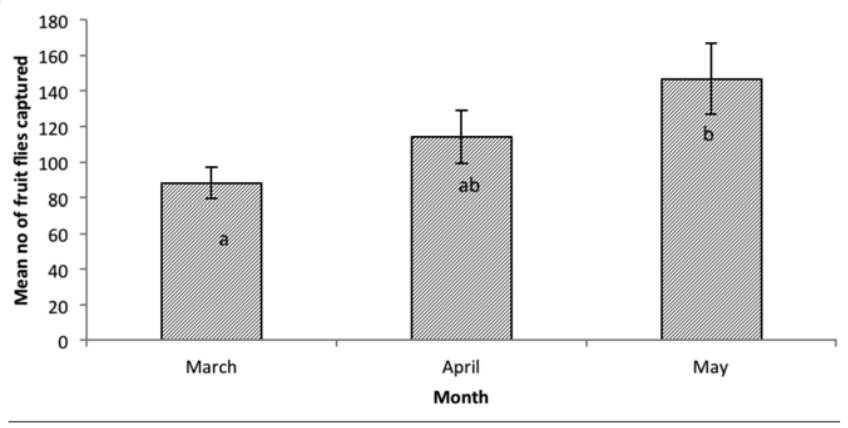

Figure 4. Number of safflower capsule flies in the months of 2009.

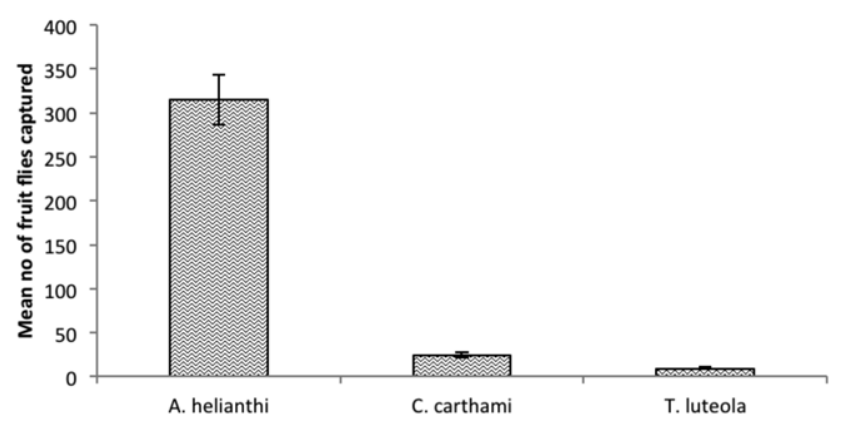

Figure 5. Number of safflower capsule flies for each species in 2009. 
there was no significant difference found between $C$. carthami and $T$. luteola. The highest number of flies per trap per week for $A$. helianthi was recorded in late May, while the highest catch for $C$. carthami was recorded in early May. The highest trap number for T. luteola was recorded in the first week of April.

Figure 8 shows the percentage of fruit fly species extracted from the incubated flower heads during the study period (2009). The trap catch numbers for the three fruit fly species were not significantly different $(\mathrm{P}<0.05)$. However, the mean number of $A$. helianthi captured during the study was significantly higher than those of $C$. carthami and T. luteola. A. helianthi was the most dominant $(\mathrm{P}<0.05)$ fruit fly species that emerged from the incubated fruits in the peak safflower season months from March to May.

Table 4 shows the correlations matrix for the three fruit fly species. The occurrence of $A$. helianthi was negatively correlated with that of $C$. carthami. Furthermore, the occurrence of $A$. helianthi was also negatively correlated with temperature, but positively correlated with relative humidity. In addition, populations of $C$. carthami were positively correlated with temperature, but negatively correlated with both relative humidity and rainfall. Populations of T. luteola did not show any significant correlations with abiotic factors.

The production of safflower in Asia is threatened by three major insect pests, namely; aphids (Homoptera: Aphididae), stem borers (Lepidoptera: Noctuidae) and fruit flies (Diptera: Tephritidae). However, only the latter cause large-scale economic damage to the safflower flower heads (Kutuk and Ozgur, 2003). For example, yield losses due to fruit flies of more than $45 \%$ have been reported in West Asia (Khouzama et al., 2002) and between 28\% to 85\% in Iran (Keyhanian, 2008; Hasanshahi and Askarianzadeh, 2012).

Studies on the species of fruit flies associated with safflower in the Gachsaran Agricultural Research Station showed that A. helianthi, $C$. carthami and T. luteola were the most important fruit fly species. The results from the present study demonstrated that $A$. helianthi was the dominant species from March to May. It was also the dominant fruit fly species that emerged from incubated safflower flower heads.

The dominance of this fruit fly species coincided with the production of flower heads in both early and late maturing safflower varieties. This could be due to the absence of flower heads on the alternative host plants such as weeds. In addition, the study period represents the arid period at the Gachsaran station, which is conducive to the population growth of $A$. helianthi (Jakhmola and Yadav, 1980). As a consequence, A. helianthi causes an enormous amount of damage to safflower flower heads, resulting in complete seed loss if appropriate control measures are not taken (Merz, 2008; Gharajerdaghi et al., 2012).

The results showed that the patterns of fruit fly population fluctuations in the safflower farm and during the study were similar (Figures 2 and 4). The population appeared in March, started increasing in April and reached its maximum in May of both years (2008 and 2009). Hasanshahi and Askarianzade (2012) reported similar results from the Tehran Province (Iran). They stated that the peak population of $A$. helianthi was observed in May. This peak period of safflower capsule fly population coincides with the ripening of the safflowers.

Keyhanian (2008) reported different results from Ghom Province in Iran. He carried out an experiment to determine the seasonal abundance and loss assessment of the safflower capsule fly on safflowers. The results showed that the adults of $A$. helianthi appeared on the safflower crop between the $1^{\text {st }}$ week of April up to $4^{\text {th }}$ week of June, and an infestation of capsules by $A$. helianthi larvae was observed from the $1^{\text {st }}$ of April to the end of June. Thereafter it declined, which was attributed to the maturity of the crop. Its maximum population in the $1^{\text {st }}$ and $2^{\text {nd }}$

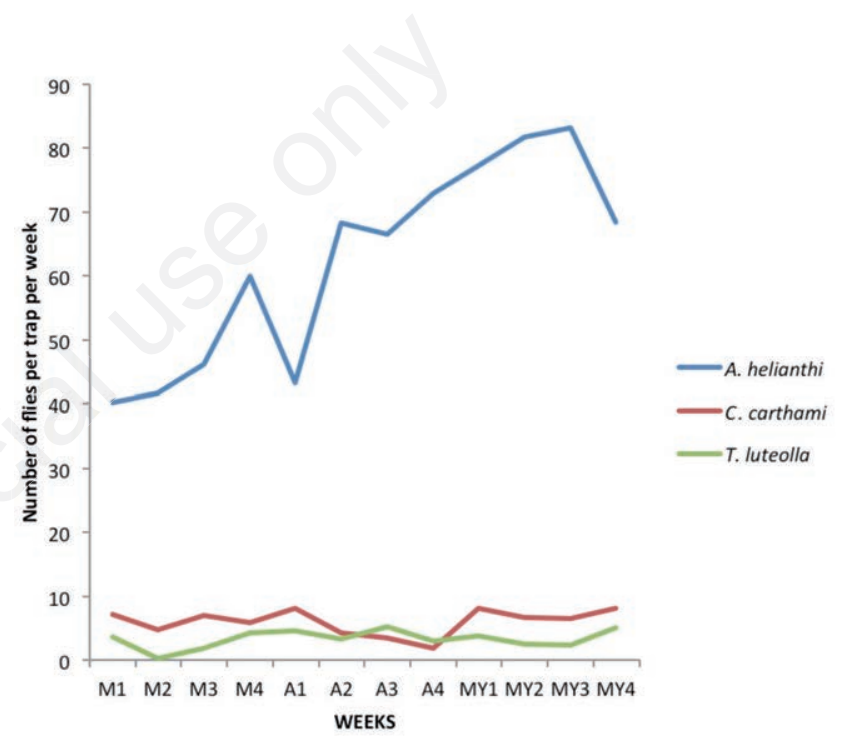

Figure 6. Mean number of fruit flies per trap per week of the three fruit fly species from March to May 2008.

Table 1. Fruit fly species recovered from incubated safflower flower heads in 2008.

\begin{tabular}{|c|c|c|c|c|}
\hline \multirow[t]{2}{*}{ Month } & \multirow{2}{*}{ Number of flower heads incubated } & \multicolumn{3}{|c|}{ Number of fruit fly species emerged } \\
\hline & & Acanthiophilus helianthi & Chaetorellia carthami & Terellia luteola \\
\hline March & 200 & 25 & 11 & 5 \\
\hline April & 200 & 85 & 40 & 9 \\
\hline May & 200 & 115 & 50 & 16 \\
\hline
\end{tabular}

Table. 2 Fruit fly species recovered from incubated safflower flower heads in 2009.

\begin{tabular}{lcccc} 
Month & Number of flower heads incubated & \multicolumn{2}{c}{$\begin{array}{c}\text { Number of fruit fly species emerged } \\
\text { Chacetorellia carthami }\end{array}$} \\
March & 200 & 90 & 10 & 5 \\
April & 200 & 120 & 20 & 12 \\
\hline May & 200 & 170 & 40 & 31 \\
\hline
\end{tabular}




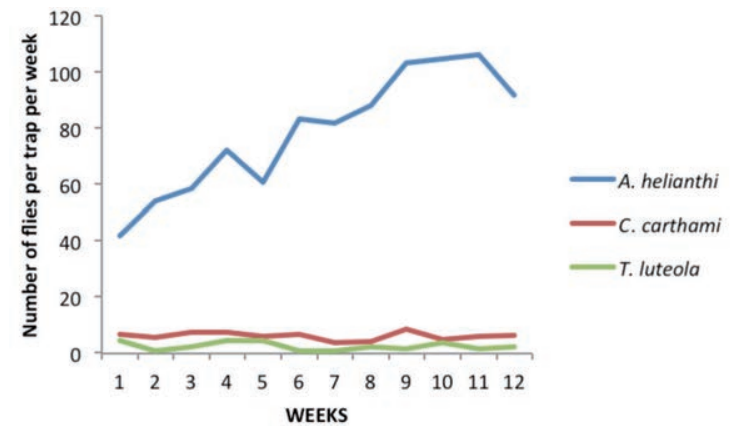

Figure 7. Mean number of fruit flies per trap per week of the three fruit fly species from March to May 2009.

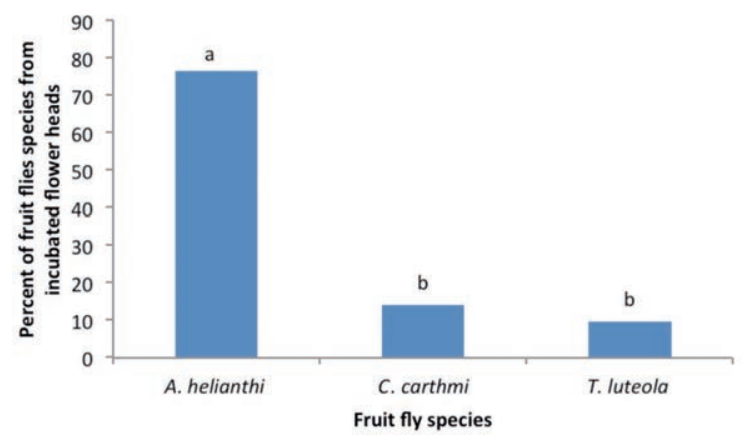

Figure 8. Percentage of fruit fly species from incubated flower heads from March to May 2009. Means with different letters are significantly different at $\mathrm{P}<0.05$. generation was seen at the last week of May and the $1^{\text {st }}$ week of June, respectively. One of the most important reasons for the different results obtained in Gachsaran and Ghom are due to the different climatic conditions and vegetation types present in these two areas.

\section{References}

DEN, D.R., WALTON M.P., 1997 - Methods in ecological and agricultural entomology. CAB International. - Wallingford, Oxon.

EMONGOR V., 2010 - Safflower (Carthamus tinctorius L.) the underutilized and neglected crop: a review. - Asian J. Plant Sci. 9: 299-306.

GHARAJEDAGHI Y.K., KHAGHANINIA S., FARSHBAF POUR ABAD R., 2012 - An investigation of the fruit flies (Diptera: Tephritidae) fauna in Ajabshir region with the new record from Iran. - Mun. Ent. Zool. 7: 1.

GILASIAN E., MERZ B., 2008 - The first report of three genera and fifteen species of Tephritidae (Diptera) from Iran. - J. Entomol. Soc. Iran 27: 11-14.

GOLKAR P., ARZANI A., REZAEI M., 2010 - Inheritance of flower colour and spinelessness in safflower (Carthamus tinctorius L.). - J. Genetics. 89: 124-127.

HASANSHAHI G.H., ASKARIANZADEH A., 2012 - Effect of drought stress on the damage safflower fly, Acanthophilus helianthi Rossi (Dip.: Tephritidae) on three cultivars of safflower, Carthamus tinctorius L. in Tehran region. - Iranian J. Entomol. Res. 4: 28-39.

JAKHMOLA S.S., YADAV H.S., 1980 - Incidence of and losses caused by capsule fly, Acanthiophilus helianthi Rossi in different varieties of safflower. - Indian J. Entomol. 42: 48-53.

KAREGAR A., ABDULAHI R., ARSLAN B., 2004 - Assessing of heritability and variance components of yield and some agronomic traits of different safflower (Carthamus tinctorius L.), cultivars. - Asian J. Plant Sci. 6: 554-557.

Table 3. Correlation coefficients $(r)$ between the occurrence of fruit flies and climatic parameters in 2008.

\begin{tabular}{lcccccc} 
& & D & E \\
Acanthiophilus helianthi (A) & A & B & C & & \\
Chaetorellia carthami (B) & 1 & & & & & \\
Terellia luteola (C) & $0.442^{*}$ & 1 & & & & \\
Precipitation (D) & 0.365 & 0.210 & 1 & & \\
\hline Relative humidity (E) & 0.292 & 0.345 & 0.128 & 1 & \\
Temperature (F) & $0.678^{*}$ & $0.535^{*}$ & 0.008 & $0.731^{*}$ & 1 \\
\hline
\end{tabular}

Numbers with asterisks are significant $(\mathrm{P}<0.05)$.

Table 4. Correlation coefficients $(r)$ between the occurrence of fruit flies and climatic parameters in 2009.

\begin{tabular}{lcccccc} 
& & D & E & \\
Acanthiophilus helianthi (A) & A & B & & & \\
Chaetorellia carthami (B) & 1 & & & & & \\
Terellia luteola (C) & $0.453^{*}$ & 1 & & & \\
Precipitation (D) & 0.389 & 0.230 & 1 & & \\
\hline Relative humidity (E) & 0.299 & 0.369 & 0.136 & 1 & 1 \\
Temperature (F) & $0.692^{*}$ & $0.565^{*}$ & 0.009 & $0.767^{*}$ & 1 \\
\hline
\end{tabular}

Numbers with asterisks are significant $(\mathrm{P}<0.05)$. 
KARIMI A., 2000 - Genetic variation in a safflower germplasm grown in rain fed cold dry lands. - J. Agron. 5: 50-52.

KEYHANIAN A.K., 2008 - Seasonal abundance of the safflower fly, Acanthiophilus helianthi Rossi (Diptera: Tephritidae), an infestation on safflower, Carthamus tinctorius L. in Ghom province, Iran. - Pajouhesh-va-Sazandegi 78: 57-62.

KHOUZAMA M.K., KALASH S.M., WHITE I.M., 2002 - Flower head infesting fruit flies (Diptera: Tephritidae) on thistles (Asteraceae). Lebanon J. Nat. His. 36: 617-626.

KORNEYEV S.V., KONOVALOV S.V., 2010 - Review of the fruit flies (Diptera: Tephritidae) of Lugansk region (Ukraine). - Summery. 1: 35-38.

KUTUK M., OZGUR A.F., 2003 - Faunistical and systematical studies on the genus Tephritis Latreille, 1804 (Diptera: Tephritidae) in the South West of Turkey along with new records. - Turk. Entomol. Derg 27: 243-252.

MAJIDI M.M., TAVAKOLI V., MIRLOHI A., SABZALIAN, M.R., 2011 - Wild safflower species (Carthamus oxyacanthus Bieb.): A possible source of drought tolerance for arid environments. - Austr. J. Crop Sci. 5: 1055-1063.
MERZ B., 2008 - Order Diptera, family Tephritidae. - Arthropod fauna of the UAE1: 643-661.

MOHAMADZADE NAMIN S., NOZARI J., NAJARPOOR A., 2010 - The fruit flies (Diptera: Tephritidae) in the fauna of Ardabil province, with new records for Iran. - Ukrainska Entomofaunistyka 1: 35-41.

RENNIE K.L., HUGHES J., LANG R., 2003 - Nutritional management of rheumatoid arthritis: a review of the evidence. - J. Hum. Nutr. Dietetics. 16: 97-109.

SAEIDI K., 2006 - Biology safflower fly, Acanthiophilus helianthi (Diptera: Tephritidae) in Gachsaran region. - Annual report office of Yasooj agricultural research center: 10-19.

SAEIDI K., MIRFAKHRAEI S., MEHRKHOU F., VALIZADEGAN 0., 2015 Biodiversity of insects associated with safflower (Carthamus tinctorius) crop in Gachsaran, Iran. - J. Entomol. Acarol. Res. 47: 26-30.

TINAY A.H., 2001 - Changes in fatty acids composition during seed growth and physiochemical characteristics of oil extracted from four safflower cultivars. - Plant Foods Hum. Nutr. 56: 385-395.

ZEYNALI E., 2001 - Simulating GFDL Predicted climate change impact on rice cropping in Iran. - J. Agric. Sci. Technol. 3: 81-90. 